\title{
A Comparative Study of 316L Stainless Steel and a Titanium Alloy in an Aggressive Biological Medium
}

\author{
Djelloul Aroussi \\ Laboratory of Applied Biomechanics and \\ Biomaterials (LABAB) \\ ENPO-MA, Oran, Algeria \\ djelloul_aroussi@hotmail.com
}

\author{
Benaoumeur Aour \\ Laboratory of Applied Biomechanics \\ and Biomaterials (LABAB) \\ ENPO-MA, Oran, Algeria \\ benaoumeur.aour@enp-oran.dz
}

\author{
Abdelhadi Sabik Bouaziz \\ Laboratory of Mechanical \\ Manufacturing and Technology \\ ENPO-MA, Oran, Algeria \\ bouaziz_sabik@hotmail.com
}

\begin{abstract}
The electrochemical behavior of stainless steel and titanium alloys is affected after prolonged contact with basic or acidic solutions, indicating a change in their surface properties. The human body often rejects invasive devices that aim to alter the biological or chemical composition of blood or other body fluids. Stents, fixation plates and screws, spinal implant devices, aneurysm clips, intramedullary nails and stems, temporary fixation devices and surgical instruments, etc. have been made from stainless steel AISI 316L for several years. Although the mechanical performance of implants and devices may be governed by their bulk properties, their interaction with the environment is managed by the characteristics of their superficial layer. In the case of biomedical devices, resistance to corrosion and biocompatibility has paramount importance. This study compares the corrosion behavior of $316 \mathrm{~L}$ stainless steel and a titanium alloy in a Hank solution. The obtained results show that the titanium alloy has a higher potential than $316 \mathrm{~L}$ stainless steel and lower corrosion current.
\end{abstract}

Keywords-corrosion; $316 \mathrm{~L}$ stainless steel; titanium; passivation; biocompatibility

\section{INTRODUCTION}

Implants are organs and devices in order to replace a missing or a damaged organ of the human body, ensuring its vital functions optimally. Biomaterials, one of the great therapeutic advances in implantation, work under biological stress and play an increasingly crucial role in our health and quality of life [1]. In order to protect people against the possible dangers and inconveniences of implants and devices, it is necessary to test sufficiently their elements without putting in danger the patient's life. This is why large-scale studies and clinical trials are required [2]. Experiments carried out over the years have shown that cells' response to the surface of the biomaterial varies according to their type and state of maturation. In vitro and in vivo tests have led several authors to conclude that the attachment of osteoblasts is reinforced by the roughness of the surface $[3,4]$. The first tests, regarding the resistance to corrosion in physiological environment, in vitro and in vivo, seem conclusive and should continue in the coming years [5]. Research was carried out for orthopedic applications, such as knee and hip prostheses [6, 7]. This type of prosthesis undergoes significant mechanical frictional stresses, causing the release of metal particles in large quantities.

Metallic biomaterials have been used in various biomedical applications for a century, due to their low cost, excellent mechanical properties and inertness [8,9]. Stainless steel and titanium alloys are frequently employed in many biomedical applications, including cardiovascular stents/valves, orthopedic prosthesis and other devices and implants used in biomedicine, because of their biocompatibility and mechanical properties, such as high strength and toughness [10,11]. Titanium alloys are extensively used due to their attractive combination of high strength, low density, and good corrosion resistance $[12,13]$. Moreover, the $316 \mathrm{~L}$ stainless steel is known for its good ductility, fatigue resistance, and high strength toughness [14, 15]. However, there is always a concern about their corrosion resistance in physiological medium and their biocompatibility $[16,17]$. The effects of surface treatment and metallic coating on the corrosion behavior and biocompatibility of surgical 316L stainless steel implants were evaluated in [18]. The experimental results indicated that $\mathrm{Nb}$ coating and surface treatment of the stainless steel improved its corrosion behavior. The structural and bio-corrosion barrier performance of Mgsubstituted fluorapatite coating on a $316 \mathrm{~L}$ stainless steel human body implant was investigated in [19], concluding in improved corrosion resistance and biocompatibility. In [20] the microstructural evolution, mechanical, sliding wear and corrosion behavior of $316 \mathrm{~L}$ stainless steel multi axially forged at $600^{\circ} \mathrm{C}$ was studied, showing that severely deformed ultrafine-grained metals have the potential to deliver improved implant performance. The electrochemical tests conducted in [21] showed that the surface enriched by molybdenum improved the corrosion resistance of the $316 \mathrm{~L}$ stainless steel.

Recently, a comparative assessment of the corrosion intensity of orthodontic arch wires made of alloy steel, nickeltitanium and titanium-molybdenum alloys, in laboratory conditions, was presented in [22]. The highest resistance to corrosion was observed in nickel-titanium alloy arch wires, while steel wires had the lowest. Surface modification allows improvements on the materials' characteristics without compromising their important bulk properties. A review on stainless steel surface modification methods provides guidance 
for selecting the appropriate modification routes, tailored for specific biomedical applications [23].

The purpose of this study is to compare the corrosion behavior of $316 \mathrm{~L}$ stainless steel and titanium alloy in a Hank's solution, utilizing electrochemical measurements, such as potentiodynamic and cyclic polarization.

\section{STUDIED MATERIALS}

AISI 316L stainless steel and titanium alloys are commonly used in the manufacturing of prostheses. The chemical composition of these materials was determined by spectroscopic analysis (Tables I and II). Samples were cut in the form of a $14 \mathrm{~mm}$ in diameter disc from cylindrical bars delivered in a raw state.

TABLE I. COMPOSITION OF 316 L STAINLESS STEEL (IN MASS \%)

\begin{tabular}{|c|c|c|c|c|c|c|c|c|c|c|c|}
\hline $\mathbf{C}$ & $\mathbf{P}$ & $\mathbf{S}$ & $\mathbf{S i}$ & $\mathbf{M n}$ & $\mathbf{C r}$ & $\mathbf{N i}$ & $\mathbf{M o}$ & $\mathbf{T i}$ & $\mathbf{N}$ & $\mathbf{C u}$ & $\mathbf{C o}$ \\
\hline 0.024 & 0.029 & 0.025 & 0.407 & 1.519 & 16.64 & 10.355 & 2.037 & 0.006 & 0.047 & 0.296 & 0.188 \\
\hline
\end{tabular}

TABLE II. COMPOSITION OF THE TITANIUM ALLOY (IN MASS \%).

\begin{tabular}{|c|c|c|c|}
\hline TI & Fe & V & Pd \\
\hline 98.44 & 0.22 & 1.33 & 0.01 \\
\hline
\end{tabular}

\section{SURFACE PROPERTIES AND POLISHING TECHNIQUES}

Optimizing the properties of surface corrosion resistance is a wide and important research topic, given its potential application in different biomedical fields. Corrosion resistance is one of surfaces' major characteristics that must be optimized in order to improve the integration of implants. In this section, focus is set on roughness and electrochemical properties. Anodic dissolution of the sample can produce excellent polishing results without deforming its surface. The sample is polarized at the anode and connected to the cathode through an electrolyte bath concentrated in acid. Applying voltage creates a current that travels through the bath and thus preferentially alters the surface to be polished. Previously, the surface of the sample was mechanically pre-polished on abrasive papers of decreasing grain size (up to 1500 grains $/ \mathrm{cm}^{2}$ ). It should be noted that for each electro-polishing treatment, a new fresh electrolyte was used because changes in the ionic metal concentration could have an influence on the electro-polishing states [24]. Consequently, the sample was cleaned by immersion in a mixture of hydrofluoric acid $(2 \% \mathrm{v} / \mathrm{v})$, nitric acid $(10 \% \mathrm{v} / \mathrm{v})$ and DI water $(88 \% \mathrm{v} / \mathrm{v})$, for $30 \mathrm{~s}$ at $50^{\circ} \mathrm{C}$, in order to dissolve the salts without attacking the metal [25]. After each operation, the sample was ultrasonically cleaned in a solution of water and acetone for 10 minutes and dried with compressed air. The roughness was measured using a "Surftest 201" portable rugosimeter. Each measurement was repeated five times at different locations and the roughness values of the samples are recorded in Table III.

TABLE III. SURFACE ROUGHNESS OF THE STUDIED MATERIALS

\begin{tabular}{|c|c|}
\hline & $\mathbf{R a}_{\text {avg }}[\boldsymbol{\mu m}]$ \\
\hline 316L (electrolytically polished) & $0.05 \pm 0.02$ \\
\hline Titanium alloy (mechanically polished) & $0.07 \pm 0.02$ \\
\hline
\end{tabular}

\section{RESULTS AND DISCUSSION}

\section{A. Microhardness}

The microhardness tests were carried out under a load of $20 \mathrm{~g}$, load from which the impression is visible under the microscope, using a Vickers microdurometer equipped with a microscope. Vickers HV hardness is related to the length of the diagonal of the impression $(d)$ and the applied load $(m)$ by:

$$
H V=1.854 m / d^{2}
$$

with $m$ in [kgf] and $d$ in [mm]. The microhardness results for both materials are shown in Table IV and represent the average of 10 measurements. It can be noted that the titanium alloy is mechanically stronger than 316L stainless steel.

TABLE IV. MICROHARDNESS OF THE TESTED SURFACES OF THE STUDIED MATERIALS

\begin{tabular}{|c|c|}
\hline Materials & Microhardness \\
\hline 316L stainless steel & $166.8 \pm 0.2 \mathrm{Hv}$ \\
\hline Titanium alloy & $354.0 \pm 0.2 \mathrm{Hv}$ \\
\hline
\end{tabular}

\section{B. Electrochemical Analysis}

\section{1) Used Solution}

The Hank solution was used as an aggressive environment, assimilated to the physiological medium prepared from the compounds given in Table $\mathrm{V}$.

TABLE V. CHEMICAL COMPOSITION OF THE HANK SOLUTION

\begin{tabular}{|c|c|}
\hline Compositions & Quantity (g/l) \\
\hline $\mathbf{N a C l}$ & 8 \\
\hline $\mathbf{C a C l}_{\mathbf{2}}$ & 0.15 \\
\hline $\mathbf{K C l}$ & 0.40 \\
\hline $\mathbf{N a H C O}$ & 0.35 \\
\hline Glucose $_{3}$ & 0.1 \\
\hline $\mathbf{M g C l}_{\mathbf{2}} \cdot \mathbf{6} \mathbf{H}_{2} \mathbf{O}$ & 0.1 \\
\hline $\mathbf{N a}_{\mathbf{2}} \mathbf{H P O}_{4} \cdot \mathbf{2 H}_{\mathbf{2}} \mathbf{O}$ & 0.6 \\
\hline $\mathbf{K H}_{\mathbf{2}} \mathbf{P O}_{\mathbf{4}}$ & 0.06 \\
\hline $\mathbf{M g S O}_{\mathbf{4}} \cdot \mathbf{7} \mathbf{H}_{\mathbf{2}} \mathbf{O}$ & 0.06 \\
\hline
\end{tabular}

\section{2) Experimental Conditions}

The samples were characterized electrochemically under the following conditions:

- A simulated physiological environment (Hank's solution of $\mathrm{PH}=7.1)$

- Environment temperature: $37^{\circ} \mathrm{C}$ (human body temperature);

- Sweep rate of the potential: $0.5 \mathrm{mV} / \mathrm{s}$

\section{3) Evolution of the Free Potential}

This technique makes possible to follow the evolution over time of the sample potential (working electrode) in an open circuit $(\mathrm{OCP})$ relative to a reference electrode. The sample was kept immersed in the electrolyte and the free electrode potential was measured as a function of time. The abandonment potential $(E a)$ is determined from the potential follow-up curves as a function of time. This potential is a characteristic of the modification of the interface between a metal and its 
environment. This simple technique provides preliminary information on the nature of the processes developed on the metal/electrolyte interface: corrosion and passivation. The general shape of the curve indicates whether the material becomes passive if there is an increase in potential as a function of time. So, free corrosion tests were performed for all treatment conditions [28]. The results shown in Figure 1 indicate that in a Hank's solution the native passive films of electrolytically polished $316 \mathrm{~L}$ steel have greater stability. Indeed, during 1 hour of immersion the potential of $316 \mathrm{~L}$ polished by electrolysis remains stable at $-63 \mathrm{mV} / \mathrm{ECS}$, in agreement with [26].

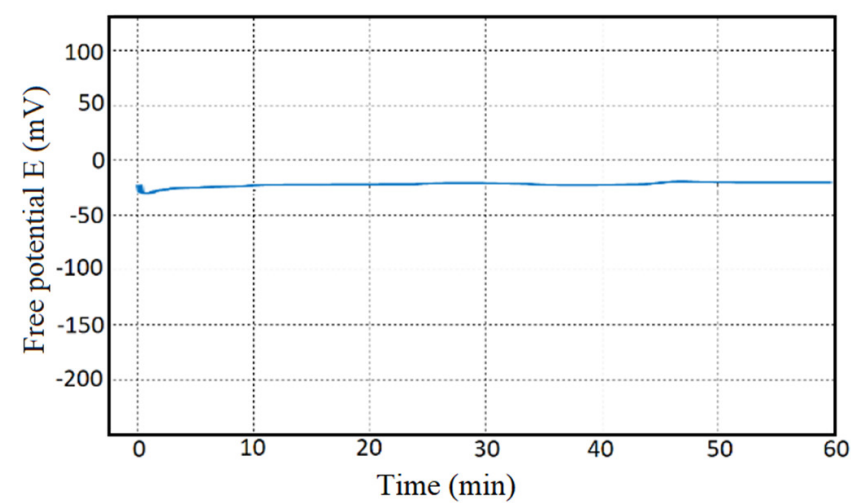

Fig. 1. Evolution of free potential as a function of time of $316 \mathrm{~L}$ steel in Hank's solution

The curve shown in Figure 2 displays an increase in potential over time. In this case, the value of the potential is rapidly stabilized, in less than 30 minutes, at about $-10 \mathrm{mV} / \mathrm{ECS}$. In addition, the anodic and cathodic reactions are rapidly balanced.

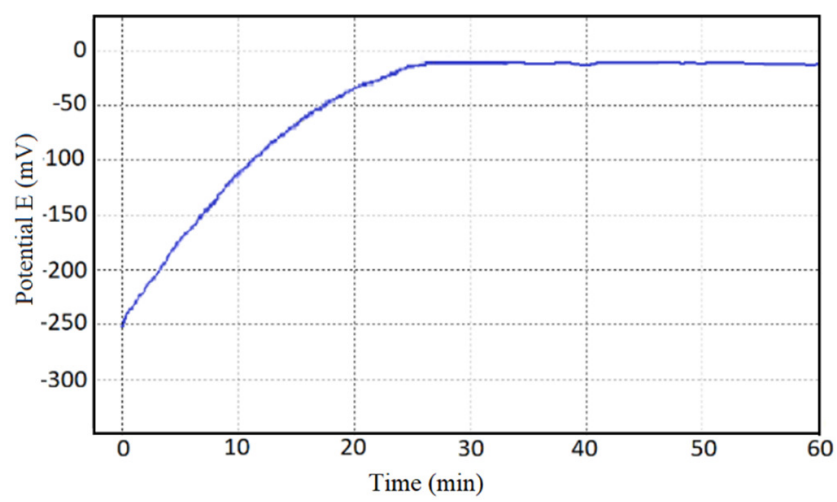

Fig. 2. Evolution of the free potential as a function of time of the titanium alloy in Hank's solution

The variation of the potential value with immersion time can be explained by the electrochemical reaction which begins to take place between the medium (Hank's solution) and the exposed surface of the metal substrate, more or less adherent, causing a relative stability of the potential for corrosion abandonment.
TABLE VI. FREE POTENTIAL RESULTS FOR STUDIED MATERIALS

\begin{tabular}{|c|c|}
\hline & $\mathbf{E}_{\text {(free) }}$ (mV/ECS) \\
\hline 316L stainless steel & -63 \\
\hline Titanium alloy & -10 \\
\hline
\end{tabular}

\section{4) Potentiodynamic Curves $\log (I)=f(E)$}

A metal immersed in any electrolytic medium tends to dissolve and electrically charge creating a double electrochemical layer, comparable to an electric battery. After a long enough time, a steady state is established and the metal electrode takes, relative to the solution, a potential called the potential corrosion (Ecor). The latter cannot be determined absolutely and it is marked with respect to a reference electrode. Using an external generator and a counter-electrode, a current passes through the metal electrode, its steady state is modified and its surface takes a new potential value (the curves $E=f(I)$ or $I=f(E)$ constitute the polarization curves). Figures 3 and 4 show the evolution of the polarization curve $\log (i)$ in terms of the potential $E$ for both materials. The potential scanning range was set at a speed of $0.5 \mathrm{mV} / \mathrm{s}$. Calculation of the density $i_{c o r}$ and corrosion potential Ecor is performed by extrapolating the anode and cathode tafel lines to the corrosion potential Ecor. The point of intersection gives us directly $i_{c o r}$ and Ecor. The corrosion rate $V_{c o r}$, expressed in ( $\mathrm{mm} /$ year), is calculated by [27]:

$$
V_{c o r}=\frac{\left(10 i_{c o r} \cdot t \cdot M\right)}{n \cdot E \cdot d}
$$

where $i_{c o r}$ is the corrosion current density $\left(\mathrm{A} / \mathrm{cm}^{2}\right), t$ is the time corresponding to years, $M$ is the average atomic mass of the studied material, $n$ is the valence, and $d$ is the density of materials.

In Figure 3, it is observed that the titanium alloy in the solution becomes passive and has a passivation plateau of the order of $500 \mathrm{mV}$. The corrosion current is very low and is of the order of $0.01 \mu \mathrm{A} / \mathrm{cm}^{2}$ (Table VII). So, the titanium alloy has a low rate of degradation $\left(60 \times 10^{-3} \mathrm{~mm} /\right.$ year $)$. In fact, the corrosion current can be likened to a residual current resulting from an ion diffusion phenomenon through the passive layer that has been formed. A break in the passivation layer was noticed beyond $+500 \mathrm{mV} / \mathrm{ECS}$. It should be noted that this break was partial because the measured currents remained low. Beyond $+1.0 \mathrm{~V} / \mathrm{ECS}$, where the overvoltage is greater, the currents increase drastically, meaning that the layer is completely broken. This state gives a good behavior against corrosion. The $316 \mathrm{~L}$ steel exhibits the same behavior as the titanium alloy. The polarization curve (Figure 4) shows a passivation level of $+500 \mathrm{mV} / \mathrm{ECS}$ and a film breaking potential of $+480 \mathrm{mV} / \mathrm{ECS}$. The corrosion current remains low, which is of the order of $2 \mu \mathrm{A} / \mathrm{cm}^{2}$ and the resistance to polarization is weak (10.7M $\Omega$ ) (Table VIII).

According to the results obtained in the Hank solution for both alloys, significant differences were noted in their electrochemical characteristics values. The corrosion potential of the titanium alloy is close to $-190.8 \mathrm{mV} / \mathrm{ECS}$ and its corrosion current density was $9.8 \times 10^{-3} \mu \mathrm{A} / \mathrm{cm}^{2}$. Compared to the $316 \mathrm{~L}$ stainless steel values, titanium's alloy values are 
clearly favorable. This alloy has greater potential than $316 \mathrm{~L}$ stainless steel and lower corrosion current. The corrosion rate for the titanium alloy is $60 \times 10^{-3} \mathrm{~mm} /$ year. This value is very acceptable in the corrosion field, showing better corrosion behavior in the Hank solution (similar to physiological environment) compared to $316 \mathrm{~L}$ stainless steel. Titanium-based alloys and stainless steels are passive materials sensitive to pitting corrosion in the presence of specific aggressive materials. These are most often chloride ions $\left(\mathrm{Cl}^{-}\right)$, which are the most aggressive and play an important role in the pitting mechanism.

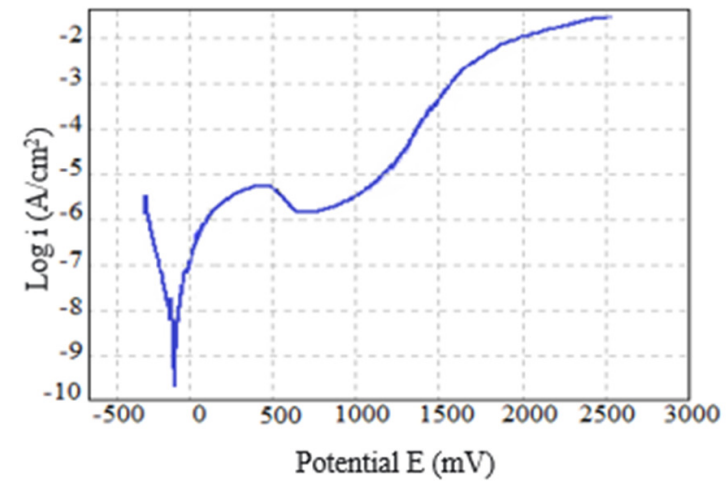

Fig. 3. Potentiodynamic curve of the titanium alloy in a Hank solution

TABLE VII. POTENTIODYNAMIC RESULTS FOR TITANIUM ALLOY

\begin{tabular}{|c|c|c|c|c|}
\hline $\begin{array}{c}\text { Corrosion } \\
\text { parameter }\end{array}$ & $\begin{array}{c}\mathbf{E}_{\text {corr }} \\
(\mathbf{m V} / \mathbf{E C S})\end{array}$ & $\begin{array}{c}\mathbf{I}_{\text {corr }} \\
\left(\boldsymbol{\mu A} / \mathbf{c m}^{2}\right)\end{array}$ & $\begin{array}{c}\mathbf{V}_{\text {corr }} \\
(\mathbf{m m} / \mathbf{y r})\end{array}$ & $\begin{array}{c}\mathbf{R p} \\
(\mathbf{M} \boldsymbol{\Omega})\end{array}$ \\
\hline Titanium alloy & -190.8 & 0.0098 & $60 \times 10^{-3}$ & 2.21 \\
\hline
\end{tabular}

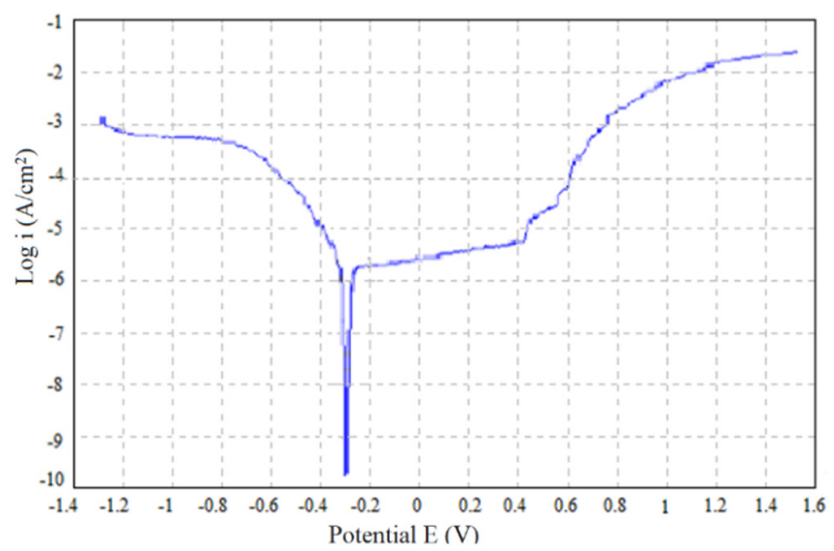

Fig. 4. Potentiodynamic curve of $316 \mathrm{~L}$ stainless steel in a Hank solution

TABLE VIII. POTENTIODYNAMIC RESULTS FOR 316L STEEL

\begin{tabular}{|c|c|c|c|c|}
\hline $\begin{array}{c}\text { Corrosion } \\
\text { parameter }\end{array}$ & $\begin{array}{c}\mathbf{E}_{\text {cor }} \\
(\mathbf{m V} / \mathbf{E C S})\end{array}$ & $\begin{array}{c}\mathbf{I}_{\text {cor }} \\
\left(\boldsymbol{\mu A} / \mathbf{c m}^{2}\right)\end{array}$ & $\begin{array}{c}\mathbf{V}_{\text {cor }} \\
(\mathbf{m m} / \mathbf{y r})\end{array}$ & $\begin{array}{c}\mathbf{R p} \\
(\mathbf{M} \mathbf{\Omega})\end{array}$ \\
\hline 316L stainless steel & -267.5 & 2.155 & $16.86 \times 10^{-3}$ & 10.7 \\
\hline
\end{tabular}

Pitting corrosion is related to localized attacks of heterogeneities that contribute to the deterioration of the passive layer protecting the material. This process of material deterioration generally leads to a generalized corrosion phenomenon. Observation by an optical microscope of the samples for both studied alloys shows the attacking shape they experienced after a corrosion test in Hank's solution (Figure 5).

(a)

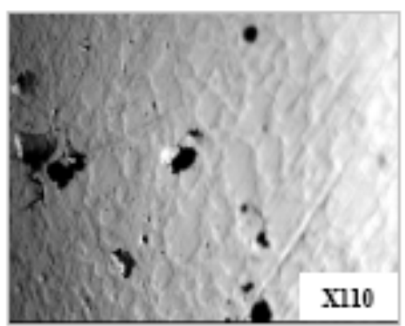

(b)

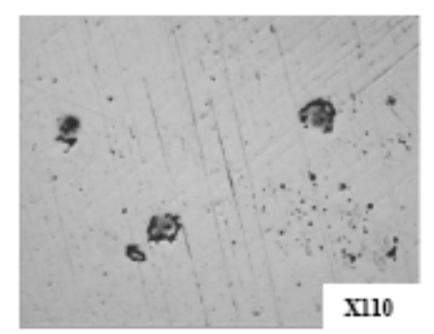

Fig. 5. Illustration of pitting corrosion in the case of (a) titanium alloy and (b) $316 \mathrm{~L}$ stainless steel

\section{5) Cyclic Potentiodynamic Curves}

The behavior of the oxide layer formed on the samples' surface was studied by drawing the cyclic potentiodynamic curves. Figure 6 shows the titanium's alloy cyclic polarization curves over a potential range for a half-hour immersion time in Hank's solution with a sweep rate of $0.5 \mathrm{mV} / \mathrm{s}$. There is a passivation stage with a slight increase in the corrosion potential compared to the previous value of EC for the "go" scan. On the other hand, during the "return" scan the corrosion potential is less great with higher current densities. This means that the formed oxide layer has instabilities. This degradation may be at the source of localized corrosion.

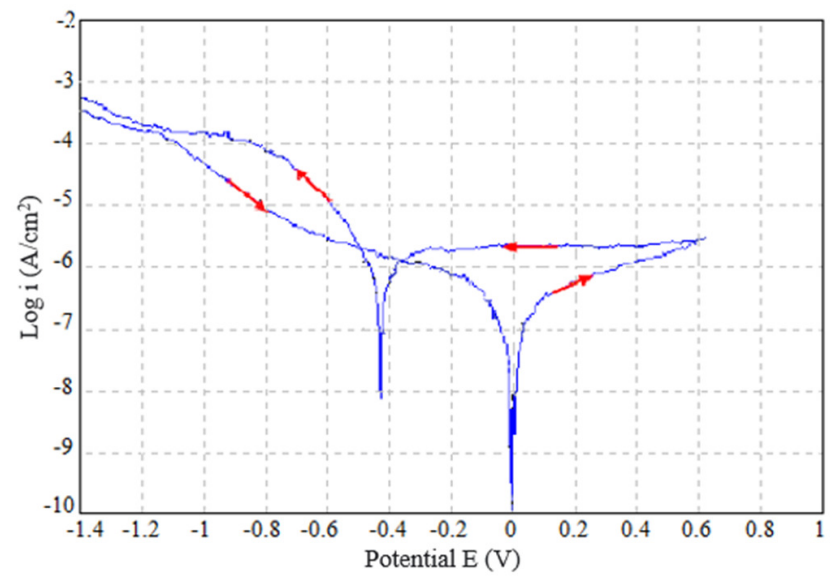

Fig. 6. Cyclic potentiodynamic polarization curve of titanium alloy

Cyclic curves in the case of $316 \mathrm{~L}$ (Figure 7) indicate a different behavior. Beyond the formation of the passivation layer on this alloy, an ennoblement of the potential corrosion in 
the anodic direction of the order of $300 \mathrm{mV}$ and very low corrosion currents were noted. Stable protective character can be established here. Tables IX and X summarize the cyclic potentiodynamic results for titanium alloy and $316 \mathrm{~L}$ stainless steel. It is noted that the polarization resistance of the titanium alloy is higher than that of $316 \mathrm{~L}$.

TABLE IX. CYCLIC POTENTIODYNAMIC RESULTS FOR THE TITANIUM ALLOY

\begin{tabular}{|c|c|c|c|c|}
\hline $\begin{array}{c}\text { Corrosion } \\
\text { parameter for the } \\
\text { Titanium alloy }\end{array}$ & $\begin{array}{c}\mathbf{E}_{\text {cor }} \\
(\mathbf{m V} / \mathbf{E C S})\end{array}$ & $\begin{array}{c}\mathbf{I}_{\text {cor }} \\
\left(\boldsymbol{\mu A} / \mathbf{c m}^{2}\right)\end{array}$ & $\begin{array}{c}\mathbf{V}_{\text {cor }} \\
(\mathbf{m m} / \mathbf{y e a r})\end{array}$ & $\begin{array}{c}\mathbf{R p} \\
(\mathbf{K} \boldsymbol{\Omega})\end{array}$ \\
\cline { 2 - 5 } & -419.0 & 0.347 & $53.62 \times 10^{-3}$ & 62.51 \\
\hline
\end{tabular}

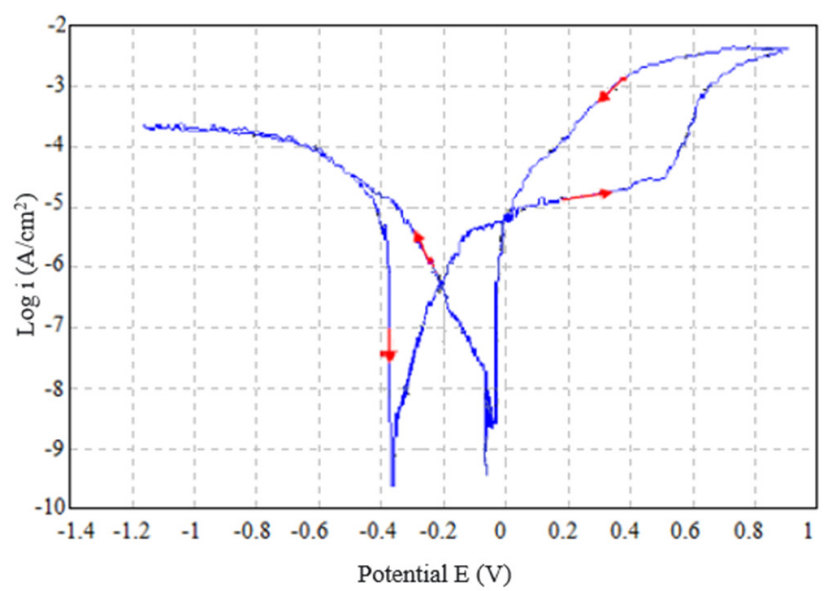

Fig. 7. Cyclic potentiodynamic polarization curve of $316 \mathrm{~L}$ stainless steel.

TABLE X. CYCLIC POTENTIODYNAMIC RESULTS FOR THE 316L STEEL

\begin{tabular}{|c|c|c|c|c|}
\hline $\begin{array}{c}\text { Corrosion } \\
\text { parameter for }\end{array}$ & $\begin{array}{c}\mathbf{E}_{\text {cor }} \\
(\mathbf{m V} / \mathbf{E C S})\end{array}$ & $\begin{array}{c}\mathbf{I}_{\text {cor }} \\
\left(\boldsymbol{\mu} \mathbf{A} / \mathbf{c m}^{2}\right)\end{array}$ & $\begin{array}{c}\mathbf{V}_{\text {cor }} \\
(\mathbf{m m} / \mathbf{y e a r})\end{array}$ & $\begin{array}{c}\mathbf{R p} \\
(\mathbf{K} \boldsymbol{\Omega})\end{array}$ \\
\cline { 2 - 6 } 316L stainless steel & -38.5 & 3.92 & $30.65 \times 10^{-3}$ & 5.54 \\
\hline
\end{tabular}

\section{CONCLUSION}

This work compared the behavior of two passive metals in a biological medium, the $316 \mathrm{~L}$ stainless steel and a titanium alloy. Several experimental techniques were used, starting with microstructural characterization and microhardness measurements for both materials. Electrochemical tests allowed the study of the biological medium's effects on the electrochemical behavior of the materials. The systems were studied by polarization curves, and were distinguished by different responses, proving that the biological medium has a great influence on the electrochemical behavior of both materials. Due to the importance of biomaterials applications, especially in the biomedical field, the samples were immersed in a Hank's solution and the evolution of the surface state was examined over time. The results obtained can be summarized as:

- Microhardness measurements show that the titanium alloy is mechanically stronger than 316L stainless steel

- The steady-state potentiodynamic curves determine equilibrium potential for both alloys.
- In the Hank's solution significant differences were found in the electrochemical characteristics. The titanium alloy had higher potential than $316 \mathrm{~L}$ stainless steel and lower corrosion current

- The use of cyclic intensity-potential curves, can help determining the quality of the passive film

- Finally, the study of the polarization resistance evolution as a function of the immersion time shows that the two alloys retain their resistance properties as a function of the immersion time in the Hank's solution.

\section{ACKNOWLEDGMENT}

The authors thank the laboratory of the ALFON complex (Algerian Foundry Society of Oran) for their support and assistance in the determination of chemical compositions by spectroscopic analysis.

\section{REFERENCES}

[1] B. D. Ratner, A. S. Hoffman, F. J. Schoen, J. E. Lemons, Biomaterials science, Academic Press, 2004

[2] L. L. Hench, E. C. Ethridge, "Biomaterials: the interfacial problem", Advances in Biomedical Engineering, Vol. 5, pp. 35-150, 1975

[3] H. J. Ronold, S. P. Lyngstadaas, J. E. Ellingsen, "Analysing the optimal value for titanium implant roughness in bone attachment using a tensile test”, Biomaterials, Vol. 24, No. 25, pp. 4559-4564, 2003

[4] A. L. Rosa, M. M. Beloti, "Effect of cpTi surface roughness on human bone marrow cell attachment, proliferation, and differentiation", Brazilial Dental Journal, Vol. 14, No. 1, pp. 16-21, 2003

[5] D. Kuroda, T. Hanawa, S. Hiromoto, Y. Katada, K. Asami, "Chararcterization of the surface oxide film of nickel-free austenitic stainless steel located in simulated body environments", Materials Transactions, Vol. 43, No. 12, pp. 3093-3099, 2002

[6] M. Fini, N. N. Aldini, P. Torricelli, G. Giavaresi, V. Borsari, H. Lenger, J. Bernauer, R. Giardino, R. Chiesa, A. Cigada, "A new austenitic stainless steel with negligible nickel content: An in vitro and in vivo comparative investigation", Biomaterials, Vol. 24, No. 27, pp. 49294939, 2003

[7] P. Torricelli, M. Fini, V. Borsari, H. Lenger, J. Bernauer, M. Tschon, V. Bonazzi, R. Giardino, "Biomaterials in orthopedic surgery: Effects of a nickel-reduced stainless steel on in vitro proliferation and activation of human osteoblasts", The International Journal of Artificial Organs, Vol. 26, No. 10, pp. 952-957, 2003

[8] M. Xiao, Y. M. Chen, M. N. Biao, X. D. Zhang, B. C. Yang, "Biofunctionalization of biomedical metals", Materials Science and Engineering: C, Vol. 70, No. 2, pp. 1057-1070, 2017

[9] H. Hermawan, D. Ramdan, J. Djuansjah, "Metals for biomedical applications", in: R. Fazel-Rezai (Ed.), Biomedical Engineering - From Theory to Applications, InTech Publications, 2011

[10] M. Niinomi, M. Nakai, J. Hieda, "Development of new metallic alloys for biomedical applications", Acta Biomaterialia, Vol. 8, No. 11, pp. 3888-3903, 2012

[11] H. Zhang, J. Han, Y. Sun, Y. Huang, M. Zhou, "MC3T3-E1 cell response to stainless steel $316 \mathrm{~L}$ with different surface treatments", Materials Science and Engineering: C, Vol. 56, pp. 22-29, 2015

[12] M. Niinomi, "Fatigue performance and cyto-toxicity of low rigidity titanium alloy, Ti-29Nb-13Ta-4.6Zr", Biomaterials, Vol. 24, No. 16, pp. 2673-2683, 2003

[13] A. W. El-Morsey, "Wear analysis of a Ti-5Al-3V-2.5Fe alloy using a factorial design approach and fractal geometry", Engineering, Technology \& Applied Science Research, Vol. 8, No. 1, pp. 2379-2384, 2018

[14] K. Touileb, A. Hedhibi, R. Djoudjou, A. Ouis, M. L. Bouazizi, "Mixing design for ATIG morphology and microstructure study of $316 \mathrm{~L}$ stainless 
steel”, Engineering,Technology \& Applied Science Research, Vol. 9, No. 2, pp. 3990-3997, 2019

[15] L. Zardiackas, Stainless steel for implants, in: Wiley Encyclopedia of Biomedical Engineering, John Wiley \& Sons, 2006

[16] G. Manivasagam, D. Dhinasekaran, A. Rajamanickam, "Biomedical implants: corrosion and its prevention: a review", Recent Patents on Corrosion Science, Vol. 2, pp. 40-54, 2010

[17] H. Hornberger, S. Virtanen, A. R. Boccaccini, "Biomedical coatings on magnesium alloys: a review", Acta Biomateralia, Vol. 8, No. 7, pp. 2442-2455, 2012

[18] A. Parsapour, S. N. Khorasani, M. H. Fathi, "Effect of surface treatment and metallic coating on corrosion behavior and biocompatibility of surgical 316L stainless steel implant”, Journal of Materials Science \& Technology, Vol. 28, No. 2, pp. 125-131, 2012

[19] A. Sharifnabi, M. H. Fathi, B. Eftekhari Yektaa, M. Hossainalipour, "The structural and bio-corrosion barrier performance of Mg-substituted fluorapatite coating on $316 \mathrm{~L}$ stainless steel human body implant", Applied Surface Science, Vol. 288, pp. 331-340, 2014

[20] S. V. Muley, A. N. Vidvans, G. P. Chaudhari, S. Udainiya, "An assessment of ultra-fine grained $316 \mathrm{~L}$ stainless steel for implant applications", Acta Biomaterialia, Vol. 30, pp. 408-419, 2016

[21] L. Jinlong, L. Tongxiang, W. Chen, "Surface enriched molybdenum enhancing the corrosion resistance of $316 \mathrm{~L}$ stainless steel", Materials Letters, Vol. 171, pp. 38-41, 2016

[22] K. Malkiewicz, M. Sztogryn, M. Mikulewicz, A. Wielgus, J. Kaminski, T. Wierzchon, "Comparative assessment of the corrosion process of orthodontic archwires made of stainless steel, titanium-molybdenum and nickel-titanium alloys", Archives of Civil and Mechanical Engineering, Vol. 18, No. 3, pp. 941-947, 2018

[23] A. Bekmurzayeva, W. J. Duncanson, H. S. Azevedo, D. Kanayeva, "Surface modification of stainless steel for biomedical applications: Revisiting a century-old material", Materials Science \& Engineering: C, Vol. 93, pp. 1073-1089, 2018

[24] J. P. Caire, E. Chainet, B. Nguyen, P. Valenti, "Study of a new stainless steel electropolishing process", in: The Proceedings of the $80^{\text {th }}$ AESF annual technical conference, American Electroplaters \& Surface Finishersw Society, 1993

[25] B. O. Elfstrom, I. Olefjord, "Preparation of alloys for ESCA investigation”, Physica Scripta, Vol. 16, No. 5-6, pp. 436-441, 1977

[26] O. Lavigne, Caracterisation des films passifs pour la definition de nouveaux materiaux : Application aux plaques bipolaires metalliques des systemes PEMFCs, PhD Thesis, INSA Lyon, 2009 (in French)

[27] H. F. Hildebrand, J. C. Hornez, "Biological response and biocompatibility", in: Metals as biomaterials, Wiley and Sons, 1998 